Research Article

\title{
Placenta Creta: A Spectrum of Lesions Associated with Shallow Placental Implantation
}

\author{
Jerzy Stanek (iD \\ Division of Pathology, Cincinnati Children's Hospital Medical Center, 3333 Burnet Avenue, Cincinnati, OH 45229, USA \\ Correspondence should be addressed to Jerzy Stanek; jerzy.stanek@cchmc.org
}

Received 16 June 2020; Revised 23 October 2020; Accepted 17 November 2020; Published 24 November 2020

Academic Editor: George Uchenna Eleje

Copyright (c) 2020 Jerzy Stanek. This is an open access article distributed under the Creative Commons Attribution License, which permits unrestricted use, distribution, and reproduction in any medium, provided the original work is properly cited.

\begin{abstract}
Background. On placental histology, placenta creta (PC) ranges from clinical placenta percreta through placenta increta and accreta (clinical and occult) to myometrial fibers with intervening decidua. This retrospective study aimed to investigate the clinicopathologic correlations of these lesions. Methods. A total of 169 recent consecutive cases with PC (group 1) were compared with 1661 cases without PC examined during the same period (group 2). The frequencies of 25 independent clinical and 40 placental phenotypes were statistically compared between the groups using chi-square test or analysis of variance where appropriate. Results. Group 1 placentas, as compared with group 2 placentas, were statistically significantly $(p<0.05)$ associated with caesarean sections $(11.2 \%$ vs. $7.5 \%)$, antepartum hemorrhage ( $17.7 \%$ vs $11.6 \%$ ), gestational hypertension ( $11.2 \%$ vs $4.3 \%)$, preeclampsia $(11.8 \%$ vs $2.6 \%)$, complicated third stage of labor (18.9\% vs $6.4 \%)$, villous infarction ( $14.2 \%$ vs $8.9 \%$ ), chronic hypoxic patterns of placental injury, particularly the uterine pattern ( $14.8 \%$, vs 9.6\%), massive perivillous fibrin deposition (9.5\% vs $5.3 \%$ ), chorionic disc chorionic microcysts ( $21.9 \%$ vs $15.9 \%)$, clusters of maternal floor multinucleate trophoblasts (27.8\% vs $21.2 \%)$, excessive trophoblasts of chorionic disc (24.3\% vs $17.3 \%$ ), segmental fetal vascular malperfusion (27.8\% vs $19.9 \%$ ), and fetal vascular ectasia (26.2\% vs $15.2 \%)$. Conclusion. Because of the association of PC with gestational hypertensive diseases, acute and chronic placental hypoxic lesions, increased extravillous trophoblasts in the chorionic disc, chorionic microcysts, and maternal floor trophoblastic giant cells, PC should be regarded as a lesion of abnormal placental implantation and abnormal trophoblast invasion rather than decidual deficiency only.
\end{abstract}

\section{Introduction}

The placenta creta (PC) spectrum is an important contributor to maternal morbidity. Several excellent reviews have discussed the clinical risk factors for PC, the most important being placenta previa, uterine scars, and previous abnormal placental separation, as well as signs and symptoms, staging (accreta, increta, and percreta), management, and clinicopathological correlation [1-7]. The incidence rate of histological placenta accreta in women with placenta praevia was $40.49 \%$ [8].

Ultrasound can be used to make a prenatal suggestion of PC spectrum disorders $[1,8]$. It is the primary method for diagnosing morbidly adherent placenta, with colour Doppler providing the best diagnostic performance, but magnetic resonance imaging should be considered when planning a resection.
The risk for major hemorrhagic morbidity after a prior pathologically diagnosed PC depends on the clinical context. Preparation for major blood loss is indicated after a prior pregnancy complicated by hemorrhage or with treatment of retained placenta with histological placenta accreta [9].

Occult PC is more common than clinical PC, but its true incidence is probably higher (sampling dependence) when more than the usual number of placental sections are obtained. In addition to clinical risk factors, basal plater myometrial fibres (BPMF) are more common when gross disruption of the basal plate is observed and sections are taken from those areas, including en face sections [10].

Clinically symptomatic cases of PC are usually associated with known risk factors or complications whereas occult PC might not be, $[6,10]$ and histological PC may occur with or without clinical suspicion of the condition. BPMF on 
placental histology are associated with an increased risk of morbidly adherent placenta in a subsequent pregnancy [11].

The roles of genetics, local hormonal factors, and the trophoblast itself have yet to be established [3]. BPMF with or without intervening decidua are the earliest clinically asymptomatic lesions of abnormal placentation. As it is tempting to include BPMF into the lesions of shallow placental implantation, this analysis aimed to investigate the clinicopathologic correlations of the spectrum of PC including all early/subclinical and clinical varieties and thereby to complement previous reports on histological features of shallow placental implantation in preeclampsia [12], massforming congenital anomalies without chromosomal abnormalities or heart malformations [13], and maternal diabetes mellitus complicated by hypertensive condition of pregnancy [14].

\section{Methods}

The study was approved by the institutional review board (IRB \#2016-7942). Placental examination was performed according to the recommendations and nomenclature of the Amsterdam Consensus Conference [15] except for some abnormal placental phenotypes that were previously defined elsewhere [16-24]. The individual placentas were examined by pediatric pathologists of the Division of Pathology (9), but all of them were re-examined by the author whose final results were included in the analysis. All gross lesions and margins of disruption of the maternal floor were sampled, the latter shaved, and at least 2 sections of the membrane rolls and the umbilical cord and 2 paracentral sections of grossly unremarkable placenta were also obtained. Formalin-fixed and paraffin-embedded sections were stained with haematoxylin and eosin ( $\mathrm{H} \& \mathrm{E})$ and were reviewed by the author.

Of 1830 consecutive placentas $>19$ of weeks gestation, examined by the author in years 2006 till 2019, 9.2\% (169 cases) showed lesions of the PC spectrum (group 1). Cases with BPMF with intervening decidua and clinical and occult placenta accreta cases are included as it appears that BPMF also correlate with the increased amount of extravillous trophoblasts and other features of shallow placental implantation.

Therefore, the inclusion criteria were findings of smooth muscle fascicles attached to maternal floor and/or placental membranes [25] with intervening decidua, myometrial fibers adjacent to the maternal floor extravillous trophoblasts or Rohr fibrinoid without intervening decidua, or myometrial fibers in direct contact with the anchoring chorionic villi, as well as cases of clinical placenta accreta, increta and percreta (Figure 1). All group 1 placentas met the above inclusion criteria. Apart from gestational age $<20$ weeks, there were no exclusion criteria. Cases in group 1 were compared to the remaining 1661 cases without PC (group 2) which were examined in the same time period. Smooth muscle actin immunostain stain was performed when eosinophilic wisps were seen at the basal plate or membrane roll to highlight muscle fibers. The frequencies of 25 independent clinical and 40 placental phenotypes were statistically compared between the groups through analysis of variance or chi-square, where appropriate.

\section{Results}

In group 1, symptomatic PC was seen in 35 cases (20.7\%): 27 cases of symptomatic placenta accreta, 3 cases of placenta increta, and 5 cases of placenta percreta, but occult PC with or without intervening decidua was by far most common (134 cases, 79.3\%), and the latter including also 2 cases of occult chorion leave accreta [25].

PC was more common in placentas from caesarean sections which was performed in $56 \%$ of the cases in group 1 and in $45 \%$ of the cases in group 2. Antepartum hemorrhage, gestational hypertension, preeclampsia and complicated third stage of labor (prolonged, postpartum blood loss), and manual extraction of placenta were also more common in group 1 (Table 1).

Of placental phenotypes (Table 2), villous infarction, chronic hypoxic patterns of placental injury, particularly the uterine pattern, massive perivillous fibrin deposition, chorionic disc chorionic microcysts, clusters of maternal floor multinucleate trophoblasts, excessive trophoblasts of chorionic disc, segmental fetal villous malperfusion (segmental avascularity, hypovascularity, and/or endothelial fragmentation by CD34 immunohistochemistry) [23], and fetal vascular ectasia were more common in group 1 (Figure 2).

\section{Discussion}

The incidence rate of PC in all studied placentas was $9.2 \%$ (Table 1). This is much higher than the $2-3 \%$ incidence rate of PC in the general population [1]. However, along with clinical PC, our material includes also occult placenta accreta and basal plate myometrial fibers with intervening decidua (Figure 1). Our $1.9 \%$ prevalence of clinical PC is therefore closer to the $2-3 \%$ incidence in general population. This study analyzed also other placental variables aside from PC in order to further clarify the pathophysiology of abnormal placental adherence and not merely to repeat previous epidemiological studies of the PC spectrum. It is not surprising that obvious associations with antepartum bleeding, more common deliveries by cesarean section, and complicated third stage of labour in Group 1 were confirmed. It is possible that the higher percentage of caesarean sections in group 1 (Table 1) resulted in more common presence of asymptomatic PC due to mechanical reason (i.e., due to manual separation of placentas during cesarean section) and not due to abnormal placental implantation, but this would require further studies.

As subclinical and clinical manifestations of abnormal placental implantation may have the same pathophysiology $[10,26]$ and tendency to recur in subsequent pregnancies, $[9,11]$ this retrospective analysis aimed at expanding our clinicoplacental studies to include the whole spectrum of PC 

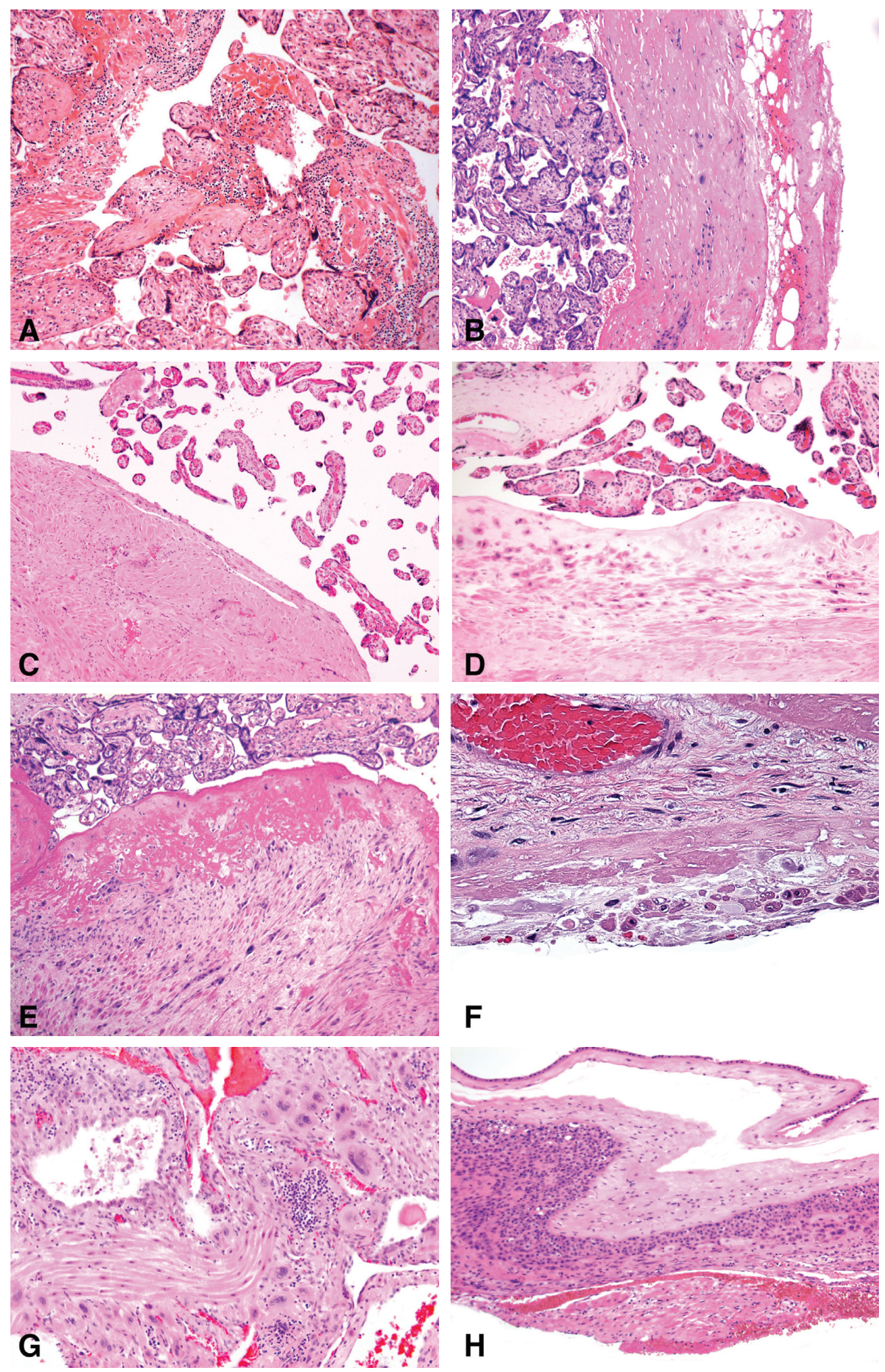

Figure 1: Placenta creta spectrum (haematoxylin and eosin, original objective magnifications are given in parentheses). (a) Placenta increta: myometrial fibers are intermingled with chorionic villi (20x). (b) Placenta percreta: placental tissue is separated from the subperitoneal fat only by fibrous tissue (10x). (c) Symptomatic placenta accreta: myometrial tissue in direct contact with the intervillous space (10x). (d) Occult placenta accreta: extravillous trophoblasts with underlying myometrial fibers in direct contact with the intervillous space (10x). (e) Occult placenta accreta: Rohr fibrinoid with an underlying mix of myometrial fibers and extravillous trophoblast (10x). (f) Basal plate myometrial fibers: Rohr fibrinoid with underlying decidua, Nitabush fibrinoid, and myometrial fibers (40x). (g) Myometrial fibers in a shaved section from a margin of disruption of the maternal floor (20x). (h) Placental membranes with adjacent myometrial fibers (chorion leave accreta) (10x). 
TABLe 1: Clinical phenotypes.

\begin{tabular}{|c|c|c|c|c|}
\hline & Group 1: placenta creta & Group 2: no placenta creta & $\begin{array}{l}F \text { or Yates } \\
\text { chi-square }\end{array}$ & $p<0.05$ \\
\hline Number of cases & 169 & 1661 & & \\
\hline Gestational hypertension & $19(11.2 \%)$ & $72(4.3 \%)$ & 15.5 & 0.001 \\
\hline Preeclampsia & $20(11.8 \%)$ & $43(2.6 \%)$ & 39.4 & 0.001 \\
\hline Chronic hypertension & $5(3.0 \%)$ & $47(2.8 \%)$ & & \\
\hline Gestational age (weeks, average \pm standard deviation) & $32.8 \pm 6.6$ & $32.3 \pm 7.4$ & & \\
\hline Maternal diabetes mellitus & $9(5.3 \%)$ & $114(6.9 \%)$ & & \\
\hline Oligohydramnios & $18(10.6 \%)$ & $153(9.2 \%)$ & & \\
\hline Polyhydramnios & $16(9.5 \%)$ & $93(5.6 \%)$ & & \\
\hline Antepartum hemorrhage & $30(17.7 \%)$ & $193(11.6 \%)$ & 5.4 & 0.020 \\
\hline Abnormal fetal heart rate tracing ${ }^{\mathrm{a}}$ & $26(15.4 \%)$ & $331(19.9 \%)$ & & \\
\hline Abnormal umbilical artery Doppler & $12(7.1 \%)$ & $242(14.6 \%)$ & & \\
\hline Induction of labor & $23(13.6 \%)$ & $309(18.6 \%)$ & & \\
\hline Placenta previa & $3(1.8 \%)$ & $11(0.7 \%)$ & & \\
\hline Cesarean section & $95(56.2 \%)$ & $750(45.1 \%)$ & 7.6 & 0.060 \\
\hline Postcesarean hysterectomy & $4(1.7 \%)$ & $1(0.7 \%)$ & & \\
\hline Multiple pregnancy & $16(9.5 \%)$ & $127(7.6 \%)$ & & \\
\hline Neonatal mortality & $21(12.4 \%)$ & $212(12.8 \%)$ & & \\
\hline Nonmacerated stillbirth & $9(5.3 \%)$ & $79(4.6 \%)$ & & \\
\hline Macerated stillbirth & $22(13.0 \%)$ & $275(16.6 \%)$ & & \\
\hline Fetal growth restriction ${ }^{\mathrm{b}}$ & $34(20.1 \%)$ & $301(18.1 \%)$ & & \\
\hline Umbilical cord compromise $^{c}$ & $16(9.5 \%)$ & $122(7.3 \%)$ & & \\
\hline Congenital malformations & $39(23.1 \%)$ & $335(20.1 \%)$ & & \\
\hline Abnormal $3^{\text {rd }}$ stage of labor (prolonged, hemorrhage) & $32(18.9 \%)$ & $107(6.4 \%)$ & 34.1 & $0.001^{\prime}$ \\
\hline Manual extraction of placenta (not during hysterectomy) & $20(11.8 \%)$ & $19(1.1 \%)$ & 84.0 & 0.001 \\
\hline
\end{tabular}

TABLe 2: Placental phenotypes.

\begin{tabular}{|c|c|c|c|c|}
\hline & $\begin{array}{l}\text { Group 1: placenta } \\
\text { creta }\end{array}$ & $\begin{array}{l}\text { Group 2: no placenta } \\
\text { creta }\end{array}$ & $\begin{array}{l}\text { Chi-square or } \\
\qquad F\end{array}$ & $p<0.05$ \\
\hline Number of cases & 169 & 1661 & & \\
\hline Placental weight (grams \pm standard deviation) & $372.8 \pm 183.4$ & $361.2 \pm 198.1$ & & \\
\hline \multicolumn{5}{|l|}{ Inflammatory lesions } \\
\hline Chronic villitis of unknown etiology & $16(9.5 \%)$ & $216(13.0 \%)$ & & \\
\hline Plasma cell deciduitis & $9(5.3 \%)$ & $81(4.9 \%)$ & & \\
\hline \multicolumn{5}{|l|}{ Hypoxic lesions/patterns } \\
\hline \multicolumn{5}{|l|}{ Acute } \\
\hline Meconium (histological) & $65(38.5 \%)$ & $710(42.7)$ & & \\
\hline Villous infarction ( $>5 \%$ of placental parenchyma) & $24(14.2 \%)$ & $148(8.9 \%)$ & 5.0 & 0.025 \\
\hline \multicolumn{5}{|l|}{ Chronic } \\
\hline Erythroblastosis of fetal blood & $32(18.9 \%)$ & $265(15.9 \%)$ & & \\
\hline Hyaline necrosis, including atherosis of spiral arterioles & $11(6.5 \%)$ & $81(4.9 \%)$ & & \\
\hline Patterns of chronic hypoxic placental injury & $49(29.0 \%)$ & $334(20.1 \%)$ & 7.3 & 0.007 \\
\hline Preuterine & $9(5.3 \%)$ & $84(5.1 \%)$ & & \\
\hline Uterine & $25(14.8 \%)$ & $159(9.6 \%)$ & 4.6 & 0.032 \\
\hline Postuterine & $15(8.9 \%)$ & $91(5.5 \%)$ & & \\
\hline Retroplacental hematoma & $9(5.3 \%)$ & $108(6.5 \%)$ & & \\
\hline Intervillous thrombus & $37(21.9 \%)$ & $294(17.7 \%)$ & & \\
\hline \multicolumn{5}{|l|}{ Shallow placental implantation } \\
\hline Membrane chorionic microcysts & $23(13.6 \%)$ & $203(12.2 \%)$ & & \\
\hline Chorionic disc extravillous trophoblast microcysts & $37(21.9 \%)$ & $264(15.9 \%)$ & 4.0 & 0.045 \\
\hline Maternal floor multinucleate trophoblast giant cells & $47(27.8 \%)$ & $352(21.2 \%)$ & 3.9 & 0.047 \\
\hline $\begin{array}{l}\text { Excessive extravillous trophoblasts in chorionic disc } \\
\text { Fetal vascular malperfusion }\end{array}$ & $41(24.3 \%)$ & $288(17.3 \%)$ & 5.0 & 0.026 \\
\hline $\begin{array}{l}\text { Fetal vascular malperfusion } \\
\text { Segmental fetal vascular malperfusion }\end{array}$ & $47(27.4 \%)$ & $330(19.9 \%)$ & 5.9 & 0.015 \\
\hline
\end{tabular}


TABLE 2: Continued.

\begin{tabular}{|c|c|c|c|c|}
\hline & $\begin{array}{l}\text { Group 1: placenta } \\
\text { creta }\end{array}$ & $\begin{array}{l}\text { Group 2: no placenta } \\
\text { creta }\end{array}$ & $\begin{array}{l}\text { Chi-square or } \\
F \\
\end{array}$ & $p<0.05$ \\
\hline Segmental stromal vascular karyorrhexis & $14(8.3 \%)$ & $100(6.0 \%)$ & & \\
\hline Segmental villous mineralization & $12(7.1 \%)$ & $146(8.8 \%)$ & & \\
\hline Fetal vascular ectasia & $45(26.2 \%)$ & $253(15.2 \%)$ & 14.6 & 0.001 \\
\hline Stem vessel obliteration & $16(9.5 \%)$ & $135(8.1 \%)$ & & \\
\hline Intramural fibrin deposition & $7(4.1 \%)$ & $124(7.5 \%)$ & & \\
\hline \multicolumn{5}{|l|}{ Other } \\
\hline $\begin{array}{l}\text { Massive perivillous fibrin deposition ( }>30 \% \text { of placental } \\
\text { parenchyma) }\end{array}$ & $16(9.5 \%)$ & $88(5.3 \%)$ & 5.0 & 0.026 \\
\hline Choriodecidual hemosiderosis & $10(5.9 \%)$ & $115(6.9 \%)$ & & \\
\hline Villous edema & $9(5.3 \%)$ & $141(8.5 \%)$ & & \\
\hline Marginal insertion of umbilical cord & $18(10.6 \%)$ & $112(6.7 \%)$ & & \\
\hline Velamentous insertion of umbilical cord & $7(4.1 \%)$ & $52(3.1 \%)$ & & \\
\hline Other umbilical cord abnormalities & $30(17.7 \%)$ & $278(16.7 \%)$ & & \\
\hline
\end{tabular}

lesions. The current opinion is that decidual deficiency rather than a primarily abnormally invasive trophoblast is most important, [5] but increased numbers of implantationsite intermediate trophoblasts were reported in hysterectomy specimens in cases of PC [27] and occult placenta accreta in nonhysterectomy placentas, [16] which would indicate that occult PC has similar histological characteristics as clinical PC and may share the same pathogenesis (decidual deficiency, abnormal trophoblast/decidua interaction, and/or hypoxia).

Several experimental studies on trophoblast proliferation and invasion in PC exist: [28] excessive protease activity, [25] decidual-trophoblastic antagonism at molecular level, [29] autocrine/paracrine actions of trophoblast-derived insulin growth factor-II in binding insulin growth factor binding protein-1 and as an integrin ligand, [30] vital kinases in mTOR pathways, [31] inflammatory cytokineenhanced matrix metalloproteinase 9, [32] and laminin binding proteins, [33] to mention a few. However, the above findings are difficult to interpret and apply in everyday clinical practice.

Routine examination of placentas may also provide information on the amount of extravillous trophoblasts: the increased extravillous trophoblast layer in placental membranes with or without chorionic microcyst formation, [20] increased number of cell islands in the chorionic disc with or without chorionic microcysts, [21, 22] and clusters of multinucleate trophoblasts at the maternal flood [34, 35]. The latter association may be indicative of poor placental implantation [36] or poor placental perfusion. [37] Based on these studies, a concept of peculiar histology of shallow placentation emerged, which was observed mostly in preeclampsia, in association with placental hypoxic lesions [12] and fetal growth restriction [38]. This analysis showed more common gestational hypertension and preeclampsia in group 1 (Table 1). However, on routine placental examination, the pattern was not uniquely associated in association with PC, being seen in other clinical situations. The PC spectrum may be thus discussed in terms of abnormal trophoblast attachment and not necessarily invasion [39].
Therefore, for the purpose of this analysis, cases of clinical PC, occult placenta accreta, and BPMF with intervening decidua were pooled together.

This analysis showed an overlap complex of chronic developmental and acute hypoxic placental lesions, fetal vascular malperfusion lesions, and lesions of shallow placental implantation in PC, as in preeclamptic placentas, [12] suggestive of similar pathophysiology reflecting maldistribution of the extravillous trophoblasts, with a large part remaining in the delivered placenta and a smaller part at the placental implantation site in the uterus, without necessarily changing the absolute numbers of extravillous trophoblasts. This also suggests that PC seen more commonly in placentas from caesarean section is unlikely due to purely mechanical reasons, but rather it is pathogenetically related to shallow placental implantation.

The process may be explained by the findings of others on the relationship of extravillous trophoblast invasion and remodeling of spiral arteries resulting in a failure of the second wave of trophoblast invasion in spontaneous abortion and early-onset fetal growth restriction with or without preeclampsia related to PC [16]. Impaired trophoblast invasion can be due to a premature increase in placental oxygen secondary to premature onset of maternal blood flow towards the placenta in the first trimester. Mechanisms such as reduced proliferation, enhanced apoptosis, or even increased fusion of extravillous trophoblasts may be responsible for the reduction of numbers of invasive trophoblasts in the myometrium [40]. Whether the dysregulation of trophoblast invasion is caused by intrinsic (trophoblastic) or environmental (decidual and arterial) factors remains to be elucidated [41, 42]. In the studied placentas, the features of shallow placental implantation were more common than the hypertensive conditions of pregnancy in group 1. Therefore, this cannot be explained solely by pure association with preeclampsia. This study also confirmed the findings of a previous analysis that PC is commonly seen with placental infarctions and chronic hypoxic patterns of placental injury, [16] similar in early-onset preeclampsia [12]. 

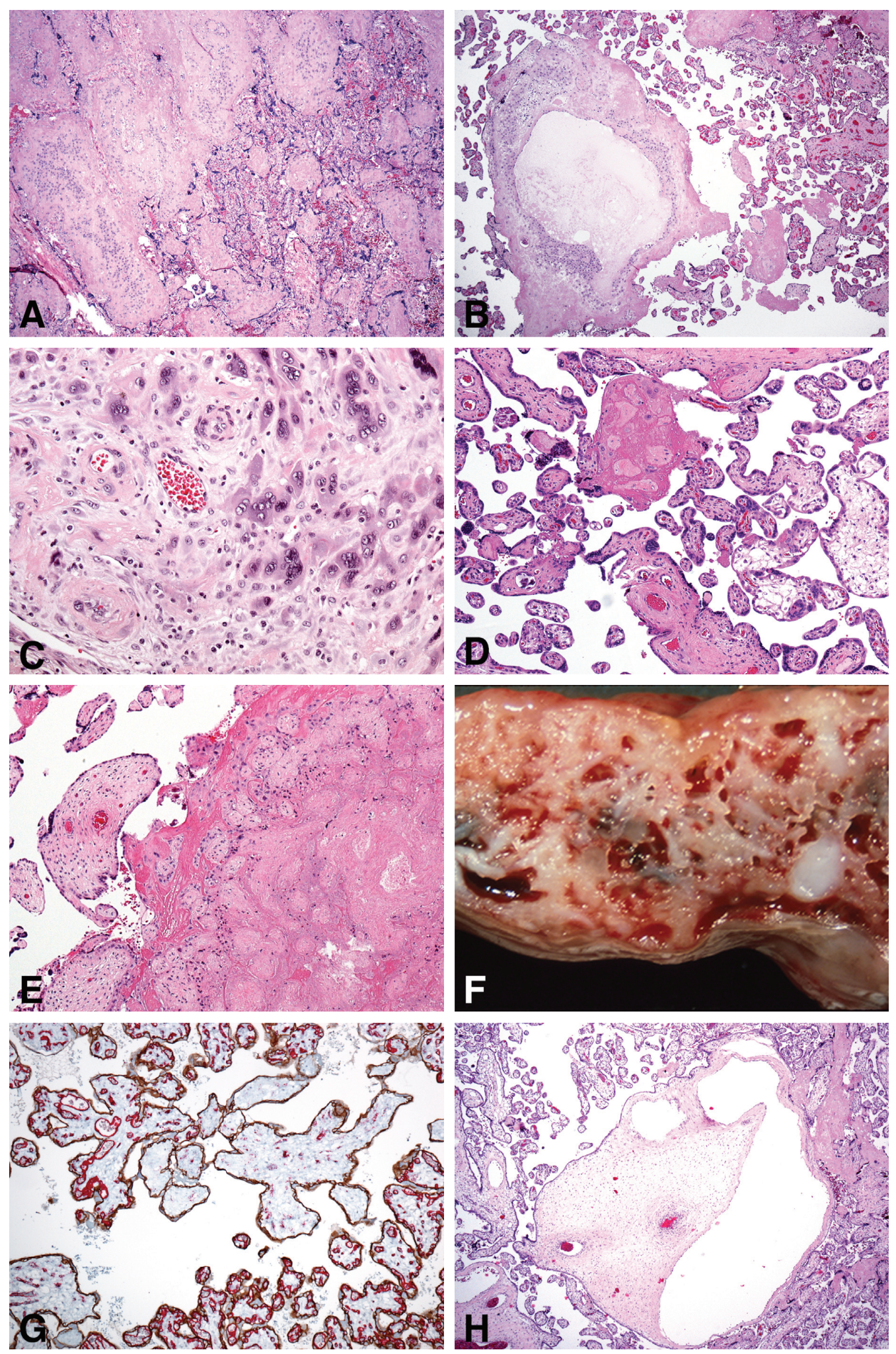

FiguRe 2: Lesions of shallow placental implantation (a-c), hypoxic lesions (d-f), and fetal vascular malperfusion lesions (g, h) statistically significant more common in group 1 (original objective magnifications are given in parentheses). (a) Confluent cell islands (excessive extravillous trophoblasts) (haematoxylin eosin, 4x). (b) Chorionic microcysts (haematoxylin eosin, 4x). (c) A cluster of multinucleate trophoblasts and hypertrophic decidual arteriopathy in maternal floor (haematoxylin eosin, 40x). (d) Uterine chronic hypoxic pattern at 34 weeks gestation (haematoxylin eosin, 10x). (e) Villous infarction (haematoxylin eosin, 10x). (f) Massive perivillous fibrinoid deposition (dissecting microscopy). (g) Incipient segmental villous hypovascularity (E cadherin (brown)/CD34 (red) immunostain, 10x). (h) Fetal stem vascular ectasia, global fetal vascular malperfusion (haematoxylin and eosin, 4x). 
The limitations of the study are its retrospective nature, the fact that the author was not blinded to the clinical information on the patients, and no control group was included. Only a comparative group was studied as no normal placentas were reviewed. Therefore, more structured research would be indicated.

In summary, although the least common, PC should be included into the spectrum of lesions of shallow placental implantation because of its association with hypertensive conditions of pregnancy, placental lesions of maternal vascular malperfusion, and other histological lesions of shallow placental implantation.

\section{Data Availability}

The data used to support the findings of this study are available upon request.

\section{Disclosure}

This work was presented at the virtual 32 Congress of the ESP and XXXIII International Congress of the IAP, 6-8 December 2020.

\section{Conflicts of Interest}

The author declares no conflicts of interest.

\section{References}

[1] A. Heerema-McKenney, E. J. Popek, and M. E. DePaepe, Diagnostic Pathology: Placenta, Amirsys, Elsevier, Philadelphia, PA, USA, 2015.

[2] F. D’Antonio, J. Palacios-Jaraquemada, P. S. Lim et al., "Counseling in fetal medicine: evidence-based answers to clinical questions on morbidly adherent placenta," Ultrasound in Obstetrics \& Gynecology, vol. 47, pp. 290-301, 2016.

[3] D. A. Carusi, "The placenta accreta: epidemiology and risk factors," Clinical Obstetrics and Gynecology, vol. 61, pp. 733-742, 2008.

[4] T. Y. Khong and W. B. Robertson, "Placenta creta and placenta praevia creta," Placenta, vol. 8, no. 4, pp. 399-409, 1987.

[5] E. Jauniaux and G. J. Burton, "Pathophysiology of placenta accreta spectrum disorders," Clinical Obstetrics and Gynecology, vol. 61, no. 4, pp. 743-754, 2018.

[6] Z. Drummond and J. Stanek, "Occult and clinical placenta creta: a case control study (abstract 11)," in Proceedings of the 50th Annual Meeting of Paediatric Pathology Society, Cape Town, South Africa, April 2004.

[7] J. Stanek and J. Biesiada, "Clustering of maternal/fetal clinical conditions and outcomes and placental lesions," American Journal of Obstetrics and Gynecology, vol. 206, 2012.

[8] D. De Vita, G. Capobianco, G. Gerosolima, C. Sciorio, E. Coppola, and F. Parazzini, "Clinical and ultrasound predictors of placenta accreta in pregnant women with antepartum diagnosis of placenta previa: a multicenter study," Gynecologic and Obstetric Investigation, vol. 84, pp. 242-247, 2019.

[9] C. Roeca, S. E. Little, and D. A. Carusi, "Pathologically diagnosed placenta accreta and hemorrhagic morbidity in a subsequent pregnancy," Obstetrics \& Gynecology, vol. 129, no. 2, pp. 321-326, 2017.
[10] T. Y. Khong and A. C. Werger, "Myometrial fibers in the placental basal plate can confirm but do not necessarily indicate clinical placenta accreta," American Journal of Clinical Pathology, vol. 116, no. 5, pp. 703-708, 2001.

[11] E. Miller, R. Linn, and L. Ernst, "Does the presence of placental basal plate myometrial fibres increase the risk of subsequent morbidly adherent placenta: a case-control study," BJOG: An International Journal of Obstetrics \& Gynaecology, vol. 123, no. 13, pp. 2140-2145, 2016.

[12] J. Stanek, "Histological features of shallow placental implantation unify early-onset and late-onset preeclampsia," Pediatric and Developmental Pathology, vol. 22, no. 2, pp. 112-122, 2019.

[13] J. Stanek, "Patterns of placental injury in congenital anomalies in second half of pregnancy," Pediatric and Developmental Pathology, vol. 22, no. 6, pp. 513-522, 2019.

[14] J. Stanek, "Decidual arteriolopathy with or without associated hypertension modifies the underlying histomorphology in placentas from diabetic mothers," Journal of Obstetrics and Gynaecology Research, vol. 43, no. 5, pp. 839-847, 2017.

[15] T. Y. Khong, E. E. Mooney, I. Ariel et al., "Sampling and definitions of placental lesions: Amsterdam placental workshop group Consensus statement," Archives of Pathology \& Laboratory Medicine, vol. 140, no. 7, pp. 698-713, 2016.

[16] J. Stanek and Z. Drummond, "Occult placenta accreta: the missing link in the diagnosis of abnormal placentation," Pediatric and Developmental Pathology, vol. 10, no. 4, pp. 266-273, 2007.

[17] J. Stanek and E. Weng, "Microscopic chorionic pseudocysts in placental membranes: a histologic lesion of in utero hypoxia," Pediatric and Developmental Pathology, vol. 10, no. 3, pp. 192-198, 2007.

[18] J. Stanek, "Diagnosing placental membrane hypoxic lesions increases the sensitivity of placental examination," Archives of Pathology \& Laboratory Medicine, vol. 134, no. 7, pp. 989-995, 2010.

[19] J. Stanek, "Acute and chronic placental membrane hypoxic lesions," Virchows Archiv, vol. 455, no. 4, pp. 315-322, 2009.

[20] J. Stanek, "Membrane microscopic chorionic pseudocysts are associated with increased amount of placental extravillous trophoblasts," Pathology, vol. 42, no. 2, pp. 125-130, 2010.

[21] J. Stanek, "Placental membrane and placental disc microscopic chorionic cysts share similar clinicopathologic associations," Pediatric and Developmental Pathology, vol. 14, no. 1, pp. 1-9, 2011.

[22] J. Stanek, "Hypoxic patterns of placental injury: a review," Archives of Pathology \& Laboratory Medicine, vol. 137, no. 5, pp. 706-720, 2013.

[23] J. Stanek and M. Abdaljaleel, "CD34 immunostain increases the sensitivity of placental diagnosis of fetal vascular malperfusion in stillbirth," Placenta, vol. 77, pp. 30-38, 2019.

[24] J. Stanek, "Segmental villous mineralization: a placental feature of fetal vascular malperfusion," Placenta, vol. 86, pp. 20-27, 2019.

[25] T. Y. Khong, S. F. Cramer, and D. S. Heller, "Chorion laeve accreta-another manifestation of morbid adherence," Placenta, vol. 74, pp. 32-35, 2018.

[26] S. G. Ren and G. D. Braunstein, "Decidua produces a protein that inhibits choriogonadotrophin release from human trophoblasts," Journal of Clinical Investigation, vol. 87, no. 1, pp. 326-330, 1991.

[27] K.-R. Kim, S.-Y. Jun, J.-Y. Kim, and J. Y. Ro, "Implantation site intermediate trophoblasts in placenta cretas," Modern Pathology, vol. 17, no. 12, pp. 1483-1490, 2004. 
[28] B. Huppertz, M. Gauster, K. Orendi, J. KÃnig, and G. Moser, "Oxygen as modulator of trophoblast invasion," Journal of Anatomy, vol. 215, no. 1, pp. 14-20, 2009.

[29] H. Katsuragawa, H. Kanzaki, T. Inoue et al., "Endometrial stromal cell decidualization inhibits human chorionic gonadotrophin and human placental lactogen secretion by cocultured trophoblasts," Human Reproduction, vol. 10, no. 11, pp. 3028-3034, 1995.

[30] J. C. Irwin, L.-F. Suen, N. A. Martina, S. P. Mark, and L. C. Giudice, "Role of the IGF system in trophoblast invasion and pre-eclampsia," Human Reproduction, vol. 14, no. 2, pp. 90-98, 1999.

[31] L. Wang, Y. Zhang, H. Qu et al., "Reduced ELABELA expression attenuates trophoblast invasion through the PI3K/ AKT/mTOR pathway in early onset preeclampsia," Placenta, vol. 87, pp. 38-45, 2019.

[32] M. Cohen, C. Wuillemin, O. Irion, and P. Bischof, "Role of decidua in trophoblastic invasion," Neuro Endocrinology Letters, vol. 31, no. 2, pp. 193-197, 2010.

[33] F. A. Vandenbrule, J. Price, M. E. Sobel, R. Lambotte, and V. Castronovo, "Inverse expression of two laminin binding proteins, 67LR and galectin-3, correlates with the invasive phenotype of trophoblastic tissue," Biochemical and Biophysical Research Communications, vol. 201, no. 1, pp. 388393, 1994.

[34] J. Stanek and J. Biesiada, "Sensitivity and specificity of finding of multinucleate trophoblastic giant cells in decidua in placentas from high-risk pregnancies," Human Pathology, vol. 43, no. 2, pp. 261-268, 2012.

[35] J. Stanek, "Placental hypoxic overlap lesions: a clinicoplacental correlation," Journal of Obstetrics and Gynaecology Research, vol. 41, no. 3, pp. 358-369, 2015.

[36] J. Stanek, "Chorionic disk extravillous trophoblasts in placental diagnosis," American Journal of Clinical Pathology, vol. 136, no. 4, pp. 540-547, 2011.

[37] B. Kemp, S. Kertschanska, M. Kadyrov, W. Rath, P. Kaufmann, and B. Huppertz, "Invasive depth of extravillous trophoblast correlates with cellular phenotype: a comparison of intra- and extrauterine implantation sites," Histochemistry and Cell Biology, vol. 117, no. 5, pp. 401-414, 2002.

[38] R. W. Redline, T. Boyd, V. Campbell et al., "Maternal vascular underperfusion: nosology and reproducibility of placental reaction patterns," Pediatric and Developmental Pathology, vol. 7, no. 3, pp. 237-249, 2004.

[39] J. Stanek and J. Biesiada, "Clustering and classical analysis of clinical and placental phenotypes in fetal growth restriction and constitutional fetal smallness," Placenta, vol. 42, pp. 93$105,2016$.

[40] B. D. Einerson, J. Comstock, R. M. Silver, P. J. Branch, A. Woodward, and A. Kennedy, "Placenta accreta spectrum disorder," Obstetrics \& Gynecology, vol. 135, no. 5, pp. 1104-1111, 2020.

[41] B. Huppertz and J. C. P. Kingdom, "Apoptosis in the trophoblast-role of apoptosis in placental morphogenesis," Journal of the Society for Gynecologic Investigation, vol. 11, no. 6, pp. 353-362, 2004.

[42] M. Gauster, G. Moser, K. Orendi, and B. Huppertz, "Factors involved in regulating trophoblast fusion: potential role in the development of preeclampsia," Placenta, vol. 30, no. 2, pp. S49-S54, 2009. 